\title{
A novel Bacillus pumilus-related strain from tropical landfarm soil is capable of rapid dibenzothiophene degradation and biodesulfurization
}

\author{
Elizandra Bruschi Buzanello ${ }^{1,2}$, Rachel Passos Rezende ${ }^{1 *}$, Fernanda Maria Oliveira Sousa ${ }^{1}$, \\ Eric de Lima Silva Marques ${ }^{1}$ and Leandro Lopes Loguercio ${ }^{1}$
}

\begin{abstract}
Background: The presence of organic sulfur-containing compounds in the environment is harmful to animals and human health. The combustion of these compounds in fossil fuels tends to release sulfur dioxide in the atmosphere, which leads to acid rain, corrosion, damage to crops, and an array of other problems. The process of biodesulfurization rationally exploits the ability of certain microorganisms in the removal of sulfur prior to fuel burning, without loss of calorific value. In this sense, we hypothesized that bacterial isolates from tropical landfarm soils can demonstrate the ability to degrade dibenzothiophene (DBT), the major sulfur-containing compound present in fuels.

Results: Nine bacterial isolates previously obtained from a tropical landfarm soil were tested for their ability to degrade dibenzothiophene (DBT). An isolate labeled as RR-3 has shown the best performance and was further characterized in the present study. Based on physiological aspects and $16 \mathrm{~s}$ rDNA sequencing, this isolate was found to be very closely related to the Bacillus pumillus species. During its growth, high levels of DBT were removed in the first 24 hours, and a rapid DBT degradation within the first hour of incubation was observed when resting cells were used. Detection of 2-hydroxybiphenyl (HBP), a marker for the 45 pathway, suggests this strain has metabolical capability for DBT desulfurization. The presence of $\mathrm{MgSO}_{4}$ in growth medium as an additional sulfur source has interfered with DBT degradation.

Conclusions: To our knowledge, this is the first study showing that a Bacillus strain can metabolize DBT via the $4 S$ pathway. However, further evidences suggest RR-3 can also use DBT (and/or its derivative metabolites) as carbon/sulfur source through another type of metabolism. Compared to other reported DBT-degrading strains, the RR-3 isolate showed the highest capacity for DBT degradation ever described in quantitative terms.

The potential application of this isolate for the biodesulfurization of this sulfur-containing compound in fuels prior to combustion was discussed.
\end{abstract}

Keywords: B. pumilus, Dibenzothiophene sulfoxide, 2-hydroxybiphenyl-2-sulfinate, 4S pathway, Bioremediation

\section{Background}

Sulfur-containing organic compounds are present as a substantial portion of petroleum, and generally display significant economic and environmental impacts. Among these, health issues (e.g. mucosal irritation and muscle and bronchial spasms), corrosion of equipment in refineries, acid rain [1,2], damage of crops (when present in the

\footnotetext{
* Correspondence: rezende.rachel@gmail.com

'Department of Biological Sciences, State University of Santa Cruz - UESC, Rod. BR 415, Km 16, 45662-900 Ilhéus, BA, Brazil

Full list of author information is available at the end of the article
}

soils), reduction of the $\mathrm{pH}$ of lakes, and increased damage to marine life [3] can be highlighted. Because those compounds can be air transported, their impact tends to be also observed at a distance from the sites of production and/or use. However, all these damages can be sharply reduced if sulfur-rich compounds are removed from petroleum and its derivatives before they go through combustion [4]. In oil refineries, various hydrodesulfurization processes are usually adopted for sulfur removal [5], although the temperature and pressure management costs are usually very high and the removal process is 
difficult and largely inefficient [6]. In this scenario, biological desulfurization is an important alternative to oil industries, as it takes place under mild conditions of temperature and energy [7]. Efficient biodesulfurization of sulfur-containing compounds is the most economically and environmentally friendly manner to eliminate this class of important pollutants from the production/ consumption chains of fossil fuels.

Studies on biodesulfurization have considered dibenzothiophene (DBT) as a model compound [8-10]. Desulfurization of this molecule is essentially achieved through either reductive or oxidative pathways that release sulfur in the form of sulfate or sulfite [10-13]. A biodesulfurization process known as the ' $4 S$ ' pathway is of particular interest, as it allows the maintenance of a large calorific value of fuels, with less potential for environmental pollution; it was discovered after a series of studies involving the Rhodococcus sp. isolate IGTS8 [14,15]. In this pathway, a specific oxidative attack against the thiophenic compound causes removal of the sulfur molecule. Briefly, this pathway displays various enzymes with different specific activities $[3,14]$, which act in the following sequence of steps [15]: a monooxygenase (the ' $\mathrm{DszC}$ ') oxidizes DBT into DBT sulfoxide (DBTO), another converts this compound into DBT sulfone $\left(\mathrm{DBTO}_{2}\right)$, which is then converted into 2-hydroxybiphenyl-2-sulfinate (HBPS); as the last step, a desulfinase (the 'DszB') withdraws sulfur from the carbon-sulfur bonds, transforming HBPS into 2-hydroxybiphenyl (HBP) and sulphate. Bacteria that use this metabolic pathway can, therefore, remove the highly toxic thiophenic compound in the form of a less aggressive inorganic substance, in a biochemical process that prevents losses of energy value $[9,11]$. Although some authors have added extra energy sources in growth media in an attempt to increase the degradation capability, the use of specialized microorganisms for the biodesulfurization procedure usually does not require media enrichment, such that the test compound (e.g. DBT) can be used as the sole source of energy for the microbial metabolism [16-18].

In a previous study, the use of DBT as an energy source was assessed in the growth of bacteria obtained from soil from an oily sludge landfarming in a tropical environment [19]; nine isolates that showed DBTconsuming ability were selected for further research. In the current work, these isolates were compared in their growth behavior in media containing DBT and were identified through sequencing. The isolate labeled as 'RR3' showed the best DBT-degrading performance and was further assessed, aiming at verifying its temporal and quantitative ability to not only degrade this compound, but also to produce HBP, one of the final products of the $4 \mathrm{~S}$ pathway resulting from the DszB enzyme activity. The results indicated this isolate as being closely related to Bacillus pumilus and as being capable of a very high and rapid degradation of DBT, likely through more than one type of metabolism.

\section{Results and discussion}

All the nine isolates under study (labeled from an 'RR' series as RR-3, $-14 \mathrm{~B},-19,-31 \mathrm{~B},-33 \mathrm{~b},-43,-52,-25 \mathrm{~A}$ and -33o) showed to be capable of biodesulfurization of oils, as they were able to grow in minimal mineral medium supplemented with DBT as the sole sulfur and carbon source. Their molecular identification was carried out by sequencing of the $16 s r R N A$ gene, obtained by PCR amplification and direct amplicon purification from each isolate. As shown in Table 1, all strains appeared to belong to the phylum Firmicutes, Bacilli class and Bacillales order. At the genus level, only the -33o isolate was classified as Paenibacillus sp (Paenibacillaceae), whereas all others appeared to belong to the Bacillus genus (Bacillaceae). Further support to the assignment of these isolates to the Bacillus genus was given by positive results for the Gram test, as well as by cells morphology under light microscopy. Seven out of the nine isolates could not be resolved between Bacillus safensis and B. pumilus based only on the sequence of this gene (Table 1 ). These two closely related species have a phylogenetic relationship that has already been fully described [20].

Nevertheless, taking into account other studies on morphological, physiological and PCR amplification aspects of this RR-3 isolate (data not shown) and the other six closely related ones (Table 1), we strongly suggest these seven isolates belong to the same species, and that they are indeed more closely related to the B. pumilus

Table 1 Taxonomic identification of nine DBT-consuming bacterial isolates through 16S rRNA gene sequencing

\begin{tabular}{llllll}
\hline Isolates & Size $(\mathbf{b p})^{\mathbf{1}}$ & Access numbers $^{\mathbf{2}}$ & Identity (\%) $^{\mathbf{3}}$ & Max score & Taxon \\
\hline$-3,-14 \mathrm{~B},-19,-31 \mathrm{~B},-33 \mathrm{~b}$, & $592-598$ & NR_074977 & 99 & 1092 & Bacillus pumilus \\
$-43,-52$ & & NR_041794 & & B. safensis \\
$-25 \mathrm{~A}$ & 598 & NR_027552 & 100 & 1105 & B. subtilis \\
-330 & 578 & NR_040884 & 96 & 955 & $\begin{array}{l}\text { Paenibacillus } \\
\text { illinoisensis }\end{array}$ \\
\hline
\end{tabular}

${ }^{7}$ Length of PCR-amplified fragment that produced good quality sequences.

${ }^{2}$ Sequences deposited in the GenBank that gave the best alignment results from BLAST search.

${ }^{3 \prime} \mathrm{e}$-values' were all equal to zero and query coverages were all $100 \%$. 
species. Interestingly, with exception of the Paenibacillus sp. isolate identified, this appears to be the first report in which isolates/species from the Bacillus genus have shown ability to grow on/metabolize DBT (Table 2). This is somewhat not surprising, as Bacillus spp is one of the most studied bacterial genus, showing a great metabolic versatility that provides the opportunity for an array of biotechnological applications [21]. Adding strength to this possibility, a recent genome sequencing of the B. pumilus S-1 strain indicated the presence of various monooxygenases [22], which could help explain at least part of the observed DBT-desulfurization phenotype of RR-3. Moreover, such genome characterization also found an array of other metabolical/biochemical capabilities, suggesting ability of this species in using a variety of carbon sources and adapting to various unfavorable conditions [22]. However, in our hands, the use of specific PCR amplification for the $d s z C$ and $d s z B$ genes (of the $4 S$ pathway) resulted in non-specific amplicons (characterized by sequencing). Moreover, sequence alignments of $d s z$ genes ( $A, B$ and $C$ ) for the Rhodococcus sp and Gordonia alkalivorans bacterial species (accession numbers L37363 and EU364831 publicly available) against the full genome of B. pumilus [22] have not provided any meaningful result (data not shown). Taken together, these results suggest the RR-3 isolate is likely bearing a specific metabolism and/or novel undescribed genes for DBT degradation that has not yet been described (see more discussion below).

These results thereby suggest that landfarm soil (at least in tropical environments) may be a rich source of

\section{Table 2 DBT degradation by different bacterial strains}

\begin{tabular}{|c|c|c|c|}
\hline $\begin{array}{l}\text { DBT degrad. } \\
\text { (\%) }\end{array}$ & $\begin{array}{l}\operatorname{Time}^{1} \\
\text { (h) }\end{array}$ & Strains & Reference \\
\hline 43 & 24 & Sphingomonas sp. & Gai, et al. [23] \\
\hline 82 & 48 & $\begin{array}{l}\text { Stenotrophomonas } \\
\text { sp. NISOC-04 }\end{array}$ & Papizadeh et al. [6] \\
\hline 50 & 120 & $\begin{array}{l}\text { Microbacterium } \\
\text { strain ZD-M2 }\end{array}$ & Li et al. [24] \\
\hline 58 & 80 & $\begin{array}{l}\text { Alcaligenes denitrificans } \\
\text { (subsp) }\end{array}$ & $\begin{array}{l}\text { Van Afferden } \\
\text { et al. [16] }\end{array}$ \\
\hline 100 & 75 & $\begin{array}{l}\text { Rhodococcus erythropolis } \\
\text { SHT87 }\end{array}$ & $\begin{array}{l}\text { Davoodi-Dehaghani } \\
\text { et al. [25] }\end{array}$ \\
\hline 60 & 120 & $\begin{array}{l}\text { Shewanella putrefaciens } \\
\text { NCIMB } 8768\end{array}$ & Ansari et al. [26] \\
\hline 83 & 120 & $\begin{array}{l}\text { Rhodococcus erythropolis } \\
\text { IGTS8 }\end{array}$ & Ansari et al. [26] \\
\hline 75 & 36 & $\begin{array}{l}\text { Rhodosporidium toruloides } \\
\text { DBVPG } 6662^{2}\end{array}$ & Baldi, et al. [27] \\
\hline 99.9 & 24 & Bacillus sp. RR-3 & This study \\
\hline
\end{tabular}

${ }^{7}$ Time of culturing/incubation in which the corresponding \% of DBT degradation on the left column was obtained.

${ }^{2}$ An yeast species. other bacterial species not yet identified or recognized as efficient DBT degraders.

With the objective of verifying the best growth performances in medium containing dibenzothiophene as the sole carbon source (minimal medium $+0.5 \mathrm{mM} \mathrm{DBT}$ ), all nine isolates were cultivated in these same conditions. The results indicated that the B. pumilus-related RR-3 isolate showed the fastest growth behavior among all, which clearly suggests an intrinsic and special capability of using DBT as an energy source compound. Based on this, we opted for pursuing further in-depth characterization only for this isolate, which was considered a representative of the group with the six other very similar B. pumilus-like isolates (Table 1).

The RR-3 isolate was further characterized with regards to not only aspects of its physiology when growing in DBT-containing LB media, but also the formation of HBP, one of the end products in the $4 \mathrm{~S}$ biodesulfurization pathway [15]. Firstly, we evaluated the kinetics of growth and DBT consumption in LB culture based on optical densities, assessing these variables in relation to presence of $\mathrm{MgSO}_{4}$ (an alternative sulfur source) and different amounts of inoculum cells (Figure 1). When these cells originated from a pre-inoculum with an OD of 0.5 at $600 \mathrm{~nm}$, the RR-3 isolate entered the exponential phase at around $12 \mathrm{~h}$ of growth (not shown), and the stationary phase between 30 and $48 \mathrm{~h}$. A different temporal pattern was noticed when the inoculum had $\sim 3 \times$ more cells: after $24 \mathrm{~h}$ of growth, a decline in OD values was observed, which went up again only after $120 \mathrm{~h}$, whereas for 0.5-OD treatments (less inoculum), such a second growth stage occurred between 72 and 96 h (Figure 1a). Parallel to this, a high DBT consumption was observed since early stages of growth. Considering the initial concentration of $500 \mu \mathrm{M}$ of DBT in the medium for both inoculum amounts, it was striking that this compound was almost completely consumed ( $>99 \%)$ after the first $24 \mathrm{~h}$ (1 - $4 \mu \mathrm{M}$ DBT left in the medium), for both 0.5 - and 1.5-OD inocula (Figure 1b), despite of their distinct growth profiles (Figure 1a). From the 48 -h time point forward, the very little remaining DBT appeared to be used up, taking longer for that to occur when inoculum was less concentrated (Figure 1b). The possibility of DBT being spontaneously degraded in such a fast rate in LB medium under the same conditions of culture can be discarded. Experiments with Arthrobacter sp. have shown strong evidence for its stability, as it remained unreacted after two weeks in a medium with boiled bacteria [28]. This was indeed confirmed experimentally in our case, based on a full recovery of applied DBT $(\sim 500 \mu \mathrm{M})$ in microbe-free LB medium, after incubation for the same time and culture conditions.

After more than $72 \mathrm{~h}$ of culture (Figure 1a), the observed OD patterns suggest a diauxy behavior for the 


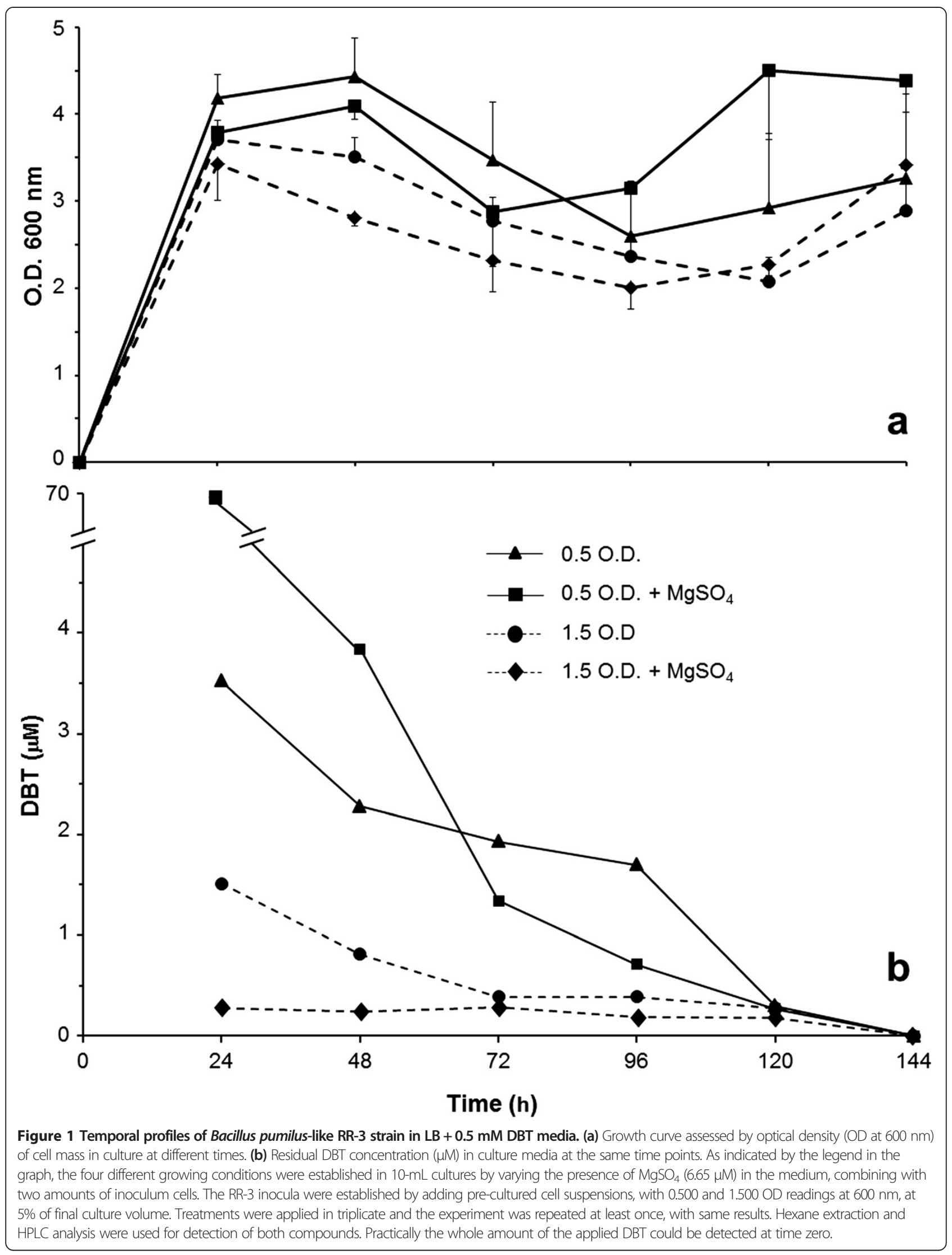


RR-3 strain, as it seemed to have entered a second growth phase. As observed by Li et al. [29] with phenol degradation such a behavior occurs when more than one energy source is, or become available in the medium. Although the activation of many genes for certain metabolisms is directly related to cell density (i.e. quorum sensing systems) [30,31], the remaining amounts of DBT after $24 \mathrm{~h}$ of growth for both inoculum concentrations (pre-inocula at 0.5 and $1.5 \mathrm{OD}$ - Figure 1b) did not allow us to verify whether this possibility was occurring with regards to sensing/signaling in relation to DBT. Nevertheless, due to the fast consumption of DBT early in culture, it is reasonable to assume that other carbon sources, either directly from the medium itself or as a consequence of culture metabolism, have likely been used for the diauxy behavior to occur. In this case, we cannot rule out the possibility of quorum sensing systems being operational at those later stages in culture, although an exact mechanism cannot be proposed at this time.

The cells of the B. pumilus-like RR-3 isolate seemed to adhere to DBT crystals, as observed at 24-h culture (data not shown). A similar behavior was observed for yeasts [27], which appears to be a strategy to reduce the cellcompound interface to facilitate enzymatic attack, despite some morphological changes that have occurred as a consequence. No cell abnormality was noted in the RR-3 isolate when attached to DBT crystals (at $1000 \times$ magnification), although this requires further in-depth observations for more conclusive results. Nevertheless, this physical attachment of RR-3 cells to DBT crystals suggest they can interact directly with this compound, and so, favored its metabolization, which may occur independently of being cultured/incubated in richer or simple media (see discussion on resting cells assays further below).

Addition of very little amounts of an alternative sulfur source $\left(\sim 7 \mu \mathrm{M} \mathrm{MgSO}_{4}\right)$ in the medium containing DBT did not lead to any clear modification in the OD values for cell mass, considering both inoculum amounts (Figure 1a). However, with regards to the DBT remaining in culture, an interesting alteration was observed: whereas $20 \times$ more DBT was observed for 0.5-OD inoculum in medium containing $\mathrm{MgSO}_{4}$, essentially no DBT was found in the same medium when culture started from the 1.5-OD inoculum (Figure $1 \mathrm{~b}$ ). These results are suggesting that a disturbing effect of $\mathrm{MgSO}_{4}$ in the metabolism of DBT by the RR-3 isolate may be observable, depending on the combination of inoculum amount and $\mathrm{MgSO}_{4}$ concentration. A similar interference on degradation pathways of organic compounds by readily available inorganic sulfur sources have also been reported in other systems [5,32]. At a higher inoculum concentration (cell density), no DBT left for consumption was found (Figure 1b); such a condition may not be unexpected, as it depends on the dynamics of DBT degradation, the initial amount of $\mathrm{MgSO}_{4}$ used, and the culturing time allowed prior to the evaluation. Considering the potential use of this B. pumilus-like isolate for either DBT biodesulfurization from fuels, or its removal from the environment in bioremediation processes, our data indicated that inorganic sulfur sources, if present in sufficient amounts, can interfere with these biodesulfurization processes. At this point, we can not state whether such interference is only of an inhibitory nature; further investigation on combining different concentrations of $\mathrm{MgSO}_{4}$ and inocula, observing these effects in earlier culture times is required to sort this out.

Detection of end products of a given pathway is an indication that such metabolism might well be operational. Hence, we assessed the presence of 2-hydroxybiphenyl (HBP) in the four media under test to verify whether the RR-3 Bacillus pumilus isolate is able to desulfurize DBT through a pathway related to the ' $4 S$ '. HBP levels ranging from 0.5 to $6.5 \mu \mathrm{M}$ were detected for all cultures and throughout all times, although $>2.5 \mu \mathrm{M}$ HBP was observed only up to $48 \mathrm{~h}$ (Figure 2). However, a detailed analysis of the results did not allow us to recognize any pattern of HBP presence/accumulation that could be associated with the patterns of DBT degradation. For instance, the high levels of DBT remaining in the $0.5-\mathrm{OD}+\mathrm{MgSO}_{4}$ medium (Figure 1b) did not correspond neither to highest nor to lowest HBP levels (Figure 2); similarly, the highest levels of HBP at 24 and $48 \mathrm{~h}$ of culture in 1.5-OD medium did not correspond to either high or low levels of remaining DBT (Figures $1 \mathrm{~b}$ and 2). Moreover, variation in cell density given by different inocula did not specifically correlate with higher or lower levels of HBP, at least under these experimental conditions.

By comparing the overall low levels of remaining DBT after only $24 \mathrm{~h}$ in culture with the $\sim 100$ times higher starting level of DBT in the media $(500 \mu \mathrm{M})$, it seems clear that a fast-consumption metabolism is occurring. In this circumstance, it would be reasonable to expect that stoichiometric high levels of HBP would be found in culture from the use of DBT at the beginning of the $4 S$ pathway. However, the relatively low overall levels $(<7 \mu \mathrm{M})$ of HBP detected and the lack of a pattern for its accumulation in the tested media (Figure 2) suggest that most of the HBP produced may have been somehow consumed or degraded after its synthesis. Alternatively, DBT and/or its derivative metabolites might have been used as carbon source in an alternative pathway [16-18], thereby preventing full operation of the $4 S$ pathway, and so, the production/accumulation of HBP. At least as observed for the culture starting with 0.5-OD inoculum, the rapid DBT consumption and detection of HBP could corroborate previous findings about the action of $4 S$-pathway enzymes during exponential growth 


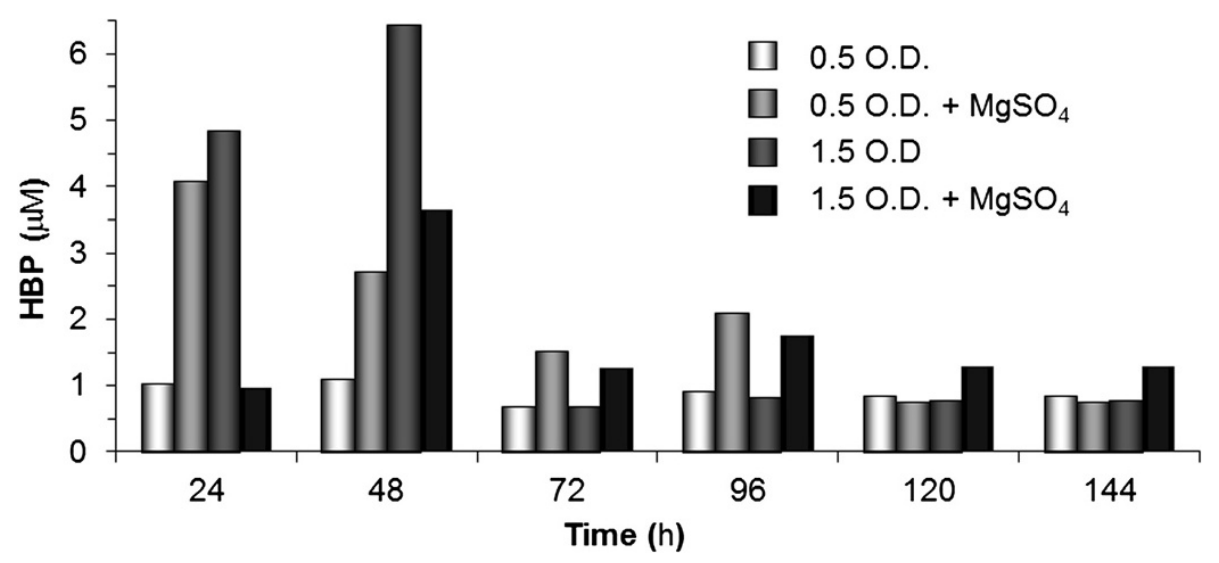

Figure 2 Detection of 2-hydroxybiphenyl (HBP) in culture of B. pumilus-like RR-3 strain in LB + 0.5 mM DBT media. HBP levels were gauged by hexane extraction and HPLC analysis. Media treatments, experimental design and culture times evaluated are the same described in Figure 1.

phase $[6,23-26,33,34]$. Although the HBP detection data would also indicate that genes related to this metabolism (such as $d s z \mathrm{C}$ and $d s z \mathrm{~B}$ ) should be operational, homologous sequences for these genes were lacking (see above), which suggest the existence of a specific mechanism and genes not yet described for DBT consumption/HBP formation in the B. pumilus-like RR-3 isolate. To account for the lack of stoichiometric relationship between DBT and HBP, the existence of another DBT-consumption metabolism that includes the destruction of the molecule ring cannot be discarded (see below). Further research involving biochemical/molecular tests and full-genome sequencing is currently underway to address this question in more details.

To our knowledge, the data presented thus far indicated this strain seems to be the fastest and most efficient degrader of DBT already described, at least at such an initial concentration of this compound in the culture media. From a series of recent studies dealing specifically with DBTdegrader microbes (Table 2), the closest efficiency in this process in relation to RR-3 was found for Stenotrophomonas sp., which showed $82 \%$ consumption of initial DBT, after $48 \mathrm{~h}$ in culture; Rhodococcus erythropolis consumed all the DBT applied, but it took $\sim 3 \times$ longer to achieve this. Considering the same 24-h time in culture for the RR-3, Sphingomonas sp showed to degrade only $43 \%$ of initial DBT (Table 2). It is worth mentioning that our working concentration for DBT in the media fell within the range of initial amounts tested in degradation studies by other microorganisms, which varied from $0.2-0.25 \mathrm{mM}$ [25] up to $0.8-1.0 \mathrm{mM}$ DBT [6]. In a report where the DBT degradation ability of Shewanella putrefaciens and Rhodococcus erythropolis were studied, normal growth occurred at initial DBT levels of $0.3 \mathrm{mM}$, but inhibitory effects were observed at concentrations $\geq$ $0.6 \mathrm{mM}[26]$.
Considering the fast DBT consumption / HPB detection observed during RR-3 growth, a further assay involving resting cells of this isolate was performed, aiming at assessing the rate of DBT degradation and possible presence of $\mathrm{HBP}$ in the first $10 \mathrm{~h}$ of exposure to DBT (Figure 3). It is worth noting that the cells in this assay were collected from a culture in logarithmic phase, with their physiology presumably set at an active metabolic state. The results confirmed a very fast consumption of DBT by this strain, with an astonishing degradation rate of $\geq 95 \%$ of initial DBT after only the first hour of incubation, depending on whether $\mathrm{MgSO}_{4}$ is present or not. Again, the presence of this alternative sulfur source delayed the use of DBT by the bacterial cells, leaving $\sim 5 \times$ more of residual DBT in the first hour and inducing its full consumption to take longer than $10 \mathrm{~h}$ (Figure 3). This finding adds further strength to the suggested interference of inorganic sulfur onto DBT metabolism by the RR-3 strain (Figure 1b; [5]). It is critical to note that this compound was present as the sole carbon source available for the cells in simple phosphate buffer. As discussed above, DBT is a very stable component, so that one should not expect any decrease in its amount only by incubation in this buffer at such a mild temperature of $30^{\circ} \mathrm{C}$ and a slow speed of 150 -rpm shaking. Therefore, such a very rapid disappearance of DBT can only be attributed to a very fast metabolization by the resting cells. Since the very low levels of HBP detected at the same time were not stoichiometric compatible to such a large DBT degradation, this, in fact, adds support to the possibility of a concomitant existence of an alternative metabolism for energy production (directly and/ or through derivative/intermediate metabolites) using DBT as carbon source. Further experiments to specifically address this question of more than one DBTconsumption pathways in RR-3 isolate are certainly warranted to clarify this issue. 


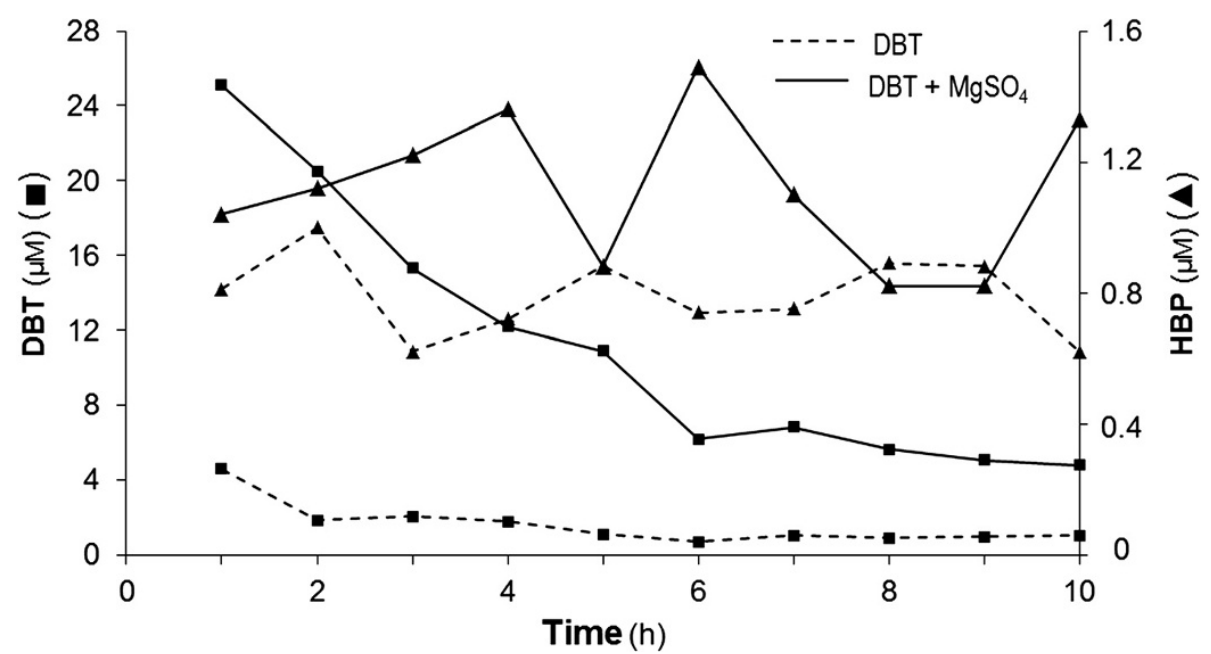

Figure 3 Kinetics of DBT consumption and HBP detection in B. pumilus-like RR-3 strain in resting cells assays. Dashed-line curves correspond to phosphate buffer + 0.5 mM DBT and solid-line curves to this medium also containing $6.65 \mu \mathrm{M} \mathrm{MgSO} \mathrm{M}_{4}$ as additional sulfur source. The inoculum of the strain was done as described, with cell amounts corresponding to a pre-inoculum suspension with a 0.500 reading of $\mathrm{OD}$ at $600 \mathrm{~nm}$. Vertical axis on the left $(\mathbf{-})$ indicate residual concentrations of DBT in the cell suspension and on the right $(\boldsymbol{\Lambda})$, the detected levels of HBP. Treatments were applied in triplicate. Detection method and levels of retrieval of the applied DBT were the same indicated in the legend of Figure 1.

Taking into account that (i) the cells were harvested when they were growing exponentially, with oxidative enzymes and their genes being expectedly active, for the resting-cells assays, (ii) DBT was readily consumed when present as the single carbon source, and (iii) in nutrientrich medium (such as LB), DBT was yet consumed during the first stages of growth in cultures that reached stationary phase and diauxy behavior later than $24 \mathrm{~h}$ (Figure 1a), it is strongly suggested that DBT consumption (as energy source and/or in a desulfurization pathway) by the B. pumilus-like RR-3 strain is metabolically preferential, when considering other carbon sources available. A high adaptation ability of this bacterium to the surrounding conditions provided by the landfarm system is a plausible explanation for this phenomenon. With regards to HBP, it was once again detected in the cell suspension at very low concentrations $(0.6-1.6 \mu \mathrm{M}$ range), with no observable accumulation pattern in relation to DBT consumption (Figure 3). Hence, based on the above discussion, HBP is likely being produced as a consequence of DBT metabolism through a 4 -like (but not equal to) pathway, but used up by the resting cells and/or not being synthesized at all, assuming in this case a concomitant DBT consumption by a different energyproduction metabolism, as mentioned above. Although HBP was found within a small concentration range, a higher oscillating behavior shown in Figure 3 for HBP presence was observed for the $\mathrm{MgSO}_{4}$-containing treatment, likely because there was DBT still left to be metabolized in the medium.

\section{Conclusions}

From this study, we concluded that (i) landfarm soil from tropical regions provides a rich source of alternative microbes and metabolisms for biodesulfurization processes; (ii) this seems to be the first report of a bacterium from the Bacillus genus (most closely related to B. pumilus) as having such a great ability in metabolizing DBT; (iii) this B. pumilus-like RR-3 strain showed the greatest degrading potential ever described for other bacterial strains, based on growth kinetics in liquid culture and resting cells assays; (iv) evidence for the preferential use of DBT as carbon source, likely in more than one type of degrading metabolism, was shown by the lack of a pattern or stoichiometric relationship between DBT consumptioin and HBP detection. Microorganisms displaying a biodesulfurization pathway in its metabolic framework similar to the '4-step' one have great biotechnological potential for DBT removal in fossil fuels production; they also have environmental significance in bioremediation strategies for polluted areas, through direct DBT consumption/degradation via other types of metabolism. Further assessment of other intermediate metabolites known to be produced by other DBT desulfurization pathways in culture are required to shed more light on the biotechnological potential of the Bacillus pumilus-like RR-3 strain.

\section{Methods}

\section{Microorganisms}

The bacterial strains used in this study were isolated by Maciel et al. [19] from landfarm soil of the Landulpho 
Alves refinery (Bahia, Brazil). They were labeled as RR-3, RR-14B, RR-19, RR-31B, RR-33b, RR-43, RR-52, RR-25A and RR-33o. The strains were inoculated in triplicate in test tubes with solid LB medium, and incubated for 24 hours at $30^{\circ} \mathrm{C}$. After growth, sterile mineral oil was added to the tubes and strains were stored either in a refrigerator at $4{ }^{\circ} \mathrm{C}$ or in freezer at $-20^{\circ} \mathrm{C}$, in Nuc tubes containing liquid $\mathrm{LB}+$ glycerol at $10 \%$ final concentration.

\section{Bacterial DNA isolation, amplification and sequencing}

The strains were inoculated into 2-mL microfuge tubes containing $1 \mathrm{~mL}$ of TY medium ( $5.0 \mathrm{~g}$ tryptone, $3.0 \mathrm{~g}$ yeast extract, $0.9 \mathrm{~g}$ dehydrated calcium chloride, $15.0 \mathrm{~g}$ agaragar per liter of doubled-distilled water). The microtubes were incubated under constant shaking of $150 \mathrm{rpm}$, at $30^{\circ} \mathrm{C}$ for $48 \mathrm{~h}$. After growth, the cultures were centrifuged for $7 \mathrm{~min}$ at $13 \mathrm{krpm}$ and the supernatant was discarded. Total DNA was extracted as described [35].

Extracted DNA was further PCR-amplified with the 16 s rDNA universal primers F27 (5'-AGAGTTTGAT CMTGGCTCAG-3') and R1525 (5'-AAGGAGGTGW TCCARCC-3') [36] in 25- $\mu \mathrm{L}$ reactions containing $3 \mathrm{mM}$ $\mathrm{MgCl}_{2}, 1 \times$ PCR buffer, $0.2 \mathrm{mM}$ each dNTP, 5 pmol each

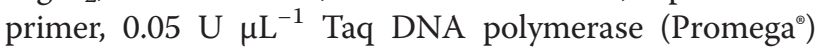
and $1.5 \mu \mathrm{L}$ DNA. Thermal cycler was programmed for amplification as follows: an initial denaturation step at $94^{\circ} \mathrm{C}$ for $5 \mathrm{~min}$, followed by 35 cycles of 1 -min denaturation at $94^{\circ} \mathrm{C}, 1$-min annealing at $57^{\circ} \mathrm{C}$, and 3 -min extension at $72^{\circ} \mathrm{C}$, with a final extension step at $72^{\circ} \mathrm{C}$ for $15 \mathrm{~min}$. Amplification was checked by electrophoresis in $1 \%$ agarose gel, with amplicons visualized through UV light after ethidium-bromide staining. DNA purification from PCR was done with $3 \mathrm{M}$ sodium acetate and absolute isopropanol on a regular precipitation-washing scheme, being further quantified by spectrophotometry. Samples were prepared as specified by the sequencingservice provider (Ludwig Biotec Inc., Porto Alegre-RS, Brazil): microtubes containing $60 \mathrm{ng}$ of purified PCR product and $4.5 \mathrm{pmol}$ of the sequencing primer F27 (5' -AGAGTTTGATCMTGGCTCAG-3') were dried in an Eppendorf 5301 'speed-vac' concentrator and sent out for sequencing (procedures are available by the service provider upon request). The electropherograms generated were analyzed by the Phred/Phrap/Consed software suites to remove low-quality sequences [37]. After processing, the nucleotide sequences were compared with those at the GenBank database, using the Basic Local Alignment Search Tool (BLAST) [38]. The softwares used for sequences alignment and dendrogram development were the 'ClustalW' and 'MEGA5' $[39,40]$, respectively. The best sequence match obtained per isolate to provide the closest taxonomic identification was based on the highest identity score, coupled with the highest size of query fragment covered in the alignment.

\section{Growth performance of isolates in DBT}

Growth behaviors in DBT were evaluated for the previously selected nine bacterial isolates, which were subjected to a two-step culturing procedure [41], based on optical density (OD) of cells, although with a modified protocol. First, a loopful of bacterial cells from stocks of each isolate was inoculated in a Petri dish containing solid LB-medium supplemented with $0.5 \mathrm{mM}$ DBT. These plates were incubated for $24 \mathrm{~h}$ at $30^{\circ} \mathrm{C}$. After growth of the isolates, a 'pre-inoculum' suspension was prepared by adding bacterial cells (scraped from the Petri dishes) in a sterile $0.85 \%$ saline solution, up to a final concentration corresponding to an OD of 0.500 at $600 \mathrm{~nm}$. In a second culturing step, $10-\mathrm{mL}$ cultures per isolate were set by adding aliquots of $0.5 \mathrm{~mL}$ of the pre-inoculum suspensions to 125 -mL flasks containing $9.5 \mathrm{~mL}$ of mineral minimal medium; this medium was prepared by adding $0.5 \mathrm{~g} \mathrm{KH}_{2} \mathrm{PO}_{4}, 4.0 \mathrm{~g} \mathrm{~K}_{2} \mathrm{HPO}_{4}, 1.0 \mathrm{~g}$ $\mathrm{NH}_{4} \mathrm{Cl}, 0.02 \mathrm{~g} \mathrm{CaCl}_{2}, 0.01 \mathrm{~g} \mathrm{NaCl}$ and $0.2 \mathrm{~g} \mathrm{MgCl}_{2}$, plus $10 \mathrm{~mL}$ of trace elements solution (containing $0.5 \mathrm{~g} / \mathrm{L} \mathrm{FeCl}_{3}, 0.5 \mathrm{~g} / \mathrm{L} \mathrm{ZnCl}_{2}, 0.5 \mathrm{~g} / \mathrm{L} \mathrm{MnCl}_{2}, 0.1 \mathrm{~g} / \mathrm{L}$ $\mathrm{Na}_{2} \mathrm{MoO}_{4}, 0.05 \mathrm{~g} / \mathrm{L} \mathrm{CuCl} 2$ and $0.05 \mathrm{~g} / \mathrm{L} \mathrm{Na}_{2} \mathrm{WO}_{4}$ ), all being dissolved directly in a liter of doubled-distilled water prior to autoclaving. DBT was added to this autoclaved medium at a $0.5 \mathrm{mM}$ final concentration as the sole carbon-sulfur source. The flasks were incubated at $150 \mathrm{rpm}$ on a rotatory bench shaker, at room temperature for $72 \mathrm{~h}$. The experiment was performed in triplicate.

\section{Growth kinetics of the selected strain}

The temporal growth pattern of the selected RR-3 isolate was determined by OD measurements at $600 \mathrm{~nm}$, with bacterial growth being assessed every 24 hours, up to 144 hours (time 'zero' was read right after inoculation). Different growth treatments were established by varying the presence of $\mathrm{MgSO}_{4}$ in DBT-containing LB medium, and the inoculum concentration, such that pre-inocula were established to ODs of 0.500 and 1.500 at $600 \mathrm{~nm}$. A volume of $0.5 \mathrm{~mL}$ of each of these pre-inocula was applied to $125-\mathrm{mL}$ flasks, each containing $9.5 \mathrm{~mL}$ liquid medium (total of $10 \mathrm{~mL}$ culture). These liquid media consisted of $\mathrm{LB}+0.5 \mathrm{mM}$ DBT, either with or without $6.65 \mu \mathrm{M} \mathrm{MgSO}$. To facilitate the measurements and to assure that aliquoting in each time point was not disturbing the culture physiology, various identical $10-\mathrm{mL}$ cultures were set, with the culturing procedure for a single flask being interrupted at each OD measurement time; therefore, seven flasks (6 time points + time 'zero') per medium type (4 medium-inoculum combinations) were established, in a total of 28 independent $10-\mathrm{mL}$ cultures, rigorously inoculated in the same way. Controls were the same media with absence of the microorganism. The experiment was performed three times, showing adequate consistency and reproducibility of results. 


\section{Resting-cells experiments}

To evaluate DBT consumption/degradation in these assays, the following procedures were performed. From colonies grown in Petri dishes containing LB medium supplemented with DBT (first-step culture), aliquots consisting of a loopful of cells were directly transferred to two 1-L flasks, each containing $500 \mathrm{~mL}$ of DBT-supplemented $(0.5 \mathrm{mM})$ LB medium, with and without $\mathrm{MgSO}_{4}$. After growth for $48 \mathrm{~h}$, these cultures were centrifuged at $3 \mathrm{Krpm}$ for $5 \mathrm{~min}$ for bacterial cells concentration. After complete removal of supernatant, the formed pellet was subjected to three washes, each with $25 \mathrm{~mL}$ phosphate buffer $(0.1 \mathrm{M}$; pH 7.0), with the final cell mass being placed into 1-L flasks containing $500 \mathrm{~mL}$ of only the phosphate buffer and thoroughly mixed. The first $1-\mathrm{mL}$ aliquot corresponding to time 'zero' was withdrawn immediately after the addition to phosphate buffer and the cell suspension was set under constant shaking at $150 \mathrm{rpm}$ and $30^{\circ} \mathrm{C}$. Further $1-\mathrm{mL}$ aliquots were hourly withdrawn for 10 hours, for hexanebased extraction (1:1) of DBT (see below). The average dry weight of the resting cells that were incubated in phosphate buffer was assessed right after the final centrifugation step. Five culture samples grown and processed in the same manner just described were oven-dried at $60^{\circ} \mathrm{C}$ for $24 \mathrm{~h}$ and weighed; the average weight of cell masses at this stage ranged from $1.6-1.7 \mathrm{~g}$.

The experiment was performed three times, showing adequate consistency and reproducibility of results.

\section{Substrate consumption and product formation during growth in DBT}

DBT consumption and 2-hydroxybiphenyl (HBP) formation were determined in culture prior to, during and after growth in LB medium containing DBT, as well as in the resting-cells assays. Both compounds were extracted with hexane at $1: 1$ ratio, by 30 min shaking at $200 \mathrm{rpm}$ and $30 \mathrm{~min}$ sonication (MaxiClean 1600). After the mixture was left resting for an appropriate time to separate the phases, the supernatant (organic phase) was analyzed by high-performance liquid chromatography, using a Shimadzu ${ }^{\circ}$ HPLC system (Kyoto, Japan) device equipped with an UV detector (SPD-20A) set at a wavelength of $248 \mathrm{~nm}$. Compounds detection and quantification were achieved by using a reversed-phase column (Gemini C18 $150 \times 4.60 \mathrm{~mm}, 5 \mu \mathrm{m}$ ) from Phenomenex ${ }^{\circ}$ (Torrance, CA, USA). The analytical conditions consisted of a mobile phase, using an isocratic system composed of $60 \%$ acetonitrile and $40 \%$ water [26], which was sonicated for $30 \mathrm{~min}$. The compounds identification was based on matching retention times for the samples components to the retention time for standard samples, assessed under the same working conditions. Media or phosphate buffer containing DBT without inoculated cells, and at time 'zero' of incubation (at inoculation), were also subjected to extraction for these components, to serve as controls for the sensitivity of the quantification method; practically $100 \%$ of the DBT applied was recovered by the evaluation technique after incubation time in cell-free media/buffer, confirming the high sensitivity and precision of measurements.

\begin{abstract}
Abbreviations
$\mathrm{SO}_{2}^{-}$: Sulphur dioxide; DBT: Dibenzothiophene; rDNA: Gene sequence for ribosomal rRNA subunit; HBP: 2-hydroxybiphenyl; DBTO: DBT sulfoxide; $\mathrm{DBTO}_{2}$ : DBT sulfone; HBPS: 2-hydroxybiphenyl-2-sulfinate; LB: Luria-Bertani culture medium; TY: Triptone-Yeast Agar medium; UV: Ultraviolet light; PCR: Polymerase chain reaction; OD: Optical density (in culture); $\mathrm{MgSO}_{4}$ : Magnesium sulphate; HPLC: High performance liquid chromatography; DszB: DBTS-monooxygenase; DszC: 2-Hidroxybiphenyl-2-sulfinato desulfinase.
\end{abstract}

\section{Competing interests}

The authors declare that they have no competing interests.

\section{Authors' contributions}

$E B B, R P R, L L L$ projected the study, assessed and interpreted the results and prepared the manuscript. EBB executed the experiments. FMOS assisted in the experiment and in the analytical interpretation of HPLC outputs. ELSM assisted in the PCR experiments, DNA sequencing, blastN, multiple sequences alignments and similarity dendrogram assembly. All authors read and approved the final manuscript.

\section{Acknowledgements}

The authors thank Dr. João Carlos Teixeira Dias for intellectual and resources inputs, and Fernanda Jordão Guimarães for technical assistance in the experiments and molecular analyses. We also wish to express our deep gratitude for the anonymous reviewers that assessed this manuscript, who provided insightful thoughts that helped improving this article substantially. This research was supported by a grant from the Brazilian funding agency for Science \& Technology - CNPq (Proc. \# 558272/2009-6). E. B. Buzanello was supported by a master's fellowship from the CNPq.

\section{Author details}

'Department of Biological Sciences, State University of Santa Cruz - UESC, Rod. BR 415, Km 16, 45662-900 Ilhéus, BA, Brazil. Faculty São Miguel do Iguaçu - UNIGUAÇU/FAESI, Rua Valentin Celeste Palavro, 1501, Jardim Panorama, 85877-000 São Miguel do Iguaçu, PR, Brazil.

Received: 13 December 2013 Accepted: 26 September 2014 Published online: 08 October 2014

\section{References}

1. Bugg TDH, Winfield CJ: Enzymatic cleavage of aromatic rings: mechanistic aspects of the catechol dioxygenases and later enzymes of bacterial oxidative cleavage pathways. Nat Prod Rep 1998, 15:513-530.

2. Kilbane JJ: Microbial biocatalyst developments to upgrade fossil fuels. Cur Opin Microbiol 2006, 17:305-314.

3. Denome SA, Olson ES, Young KD: Identification and cloning of genes involved in specific desulfurization of dibenzothiophene by Rhodococcus sp. Strain IGTS8. Appl Environ Microbiol 1993, 59:837-2843.

4. Kobayashi M, Horiuchi K, Yoshikawa O, Hirasawa K, Ishii Y, Fujino K, Sugiyama H, Maruhashi K: Kinetic analysis of microbial desulfurization of model and light gas oil: containing multiple alkyl dibenzothiophenes. Rev Biosc Biotechnol Biochem 2001, 65(2):298-304.

5. Mohebali G, Ballb AS, Rasekha B, Kaytasha A: Biodesulfurization potential of a newly isolated bacterium Gordonia alkanivorans RIPI90A. Enz Microbiol Tech 2008, 40:578-584.

6. Papizadeh M, Ardakani MR, Motamedi H, Rasouli I, Zarei M: C-S targeted biodegradation of dibenzothiophene by Stenotrophomonas sp. NISOC-04. Appl Biochem Biotechnol 2011, 165:938-948.

7. Abbad-Andaloussi S, Warzywoda M, Monot F: Microbial desulfurization of diesel oils by selected bacterial strains. Rev IFP 2003, 58(4):505-513.

8. Chen H, Zhang WJ, Cai YB, Zhang Y, Li W: Elucidation of 2-hydroxybiphenyl effect on dibenzothiophene desulfurization by Microbacterium sp. strain ZD-M2. Rev Bior Technol 2008, 99:6928-6933. 
9. Ardakani MR, Aminsefat A, Rasekh B, Yazdiyan F, Zargar B, Zarei M, Najafzadeh H: Biodesulfurization of Dibenzotiophene by a newly isolated Stenotrophomonas maltophilia strain Kho1. J W App/ Scienc 2010, 10(3):272-278

10. Xu W, Zhou W, Huang W, Pan J, Li H, Wu X, Yan Y: Preparation and evaluation of a novel surface-imprinted polymer for selective adsorption of dibenzothiophene. Microchim Acta 2011, 175:167-175.

11. GILBERT SC, Morton J, Buchanan S, Oldfield C, McRoberts A: Isolation of a unique benzothiophene-desulphurizing bacterium, Gordonia sp. Strain $213 \mathrm{E}$ (NCIMB 40816), and characterization of the desulphurization pathway. Microbiology 1998, 144:2545-2553.

12. Konishi J, Onaka T, Ishii Y, Suzuki M: Demonstration of the carbon-sulfur bond targeted desulfurization of benzothiophene by thermophilic Paenibacillus sp. strain A11-2 capable of desulfurization of dibenzothiophene FEMS Microbiol Lett 2000, 187:151-215.

13. Matsui T: Alkylated benzothiophene desulfurization by Rhodococcus sp. strain T09. Biosc Biotechnol Biochem 2000, 64:596-599.

14. Kayzer KJ, Bielaga-Jones BA, Jackowski K, Odusan O, Kilbane JJ II: Utilization of organosulphur compounds by axenic and mixed cultures of Rhodococcus IGTS8. J Gen Microbiol 1993, 139:3123-3129.

15. Ma T: The desulfurization pathway in Rhodococcus. In Biology of Rhodococcus, Microbiology Monographs series, Volume 16. Edited by Alvarez HM. Berlin Heidelberg: Springer; 2010:207-230. (Chp 8). doi:10.1007/978-3-642-12937-7_8.

16. Van Afferden M, Tappea D, Beyera M, Trüper HG, Kleina J: Biochemical mechanisms for the desulfurization of coal-relevant organic sulfur compounds. Fuel 1993, 72:1635-1643.

17. Duarte GF, Rosado AS, Seldin L, De Araujo W, Van Elsas JD: Analysis of bacterial community structure in sulfurous-oil-containing soils and detection of species carrying dibenzothiophene desulfurization (Dsz) genes. Appl Environ Microbiol 2001, 67(3):1052-1062.

18. Hamme JDV, Singh A, Ward OP: Recent advances in petroleum microbiology. Rev Microbiol Molec Biol 2003, 67(4):503-549.

19. Maciel BM, Dias JC, Dos Santos AC, Filho RC, Fontana R, Loguercio LL, Rezende RP: Microbial surfactant activities from a petrochemical landfarm in a humid tropical region of Brazil. J Can Microbiol 2007 53:937-943

20. Satomi M, La Duc MT, Venkateswaran K: Bacillus safensis sp. nov., isolated from spacecraft and assembly-facility surfaces. J Syst Ev Microbiol 2006, 56:1735-1740.

21. Duarte EAA, Lacerda GV Jr, De Oliveira TA, Brendel M, Loguercio LL, Cascardo JC: Bioprospection of bacteria and yeasts from Atlantic Rainforest soil capable of growing in crude-glycerol residues. Gen $\mathrm{Mol}$ Res 2013, 67(3):1052-1062.

22. Su F, Hua D, Zhang Z, Wang X, Tang H, Tao F, Tai C, Wu Q, Wu G, Xu P: Genome sequence of Bacillus pumilus $S-1$, an efficient isoeugenol-utilizing producer for natural vanillin. J Bacterio/ 2011, 193:6400-6401.

23. Gai Z, Yu B, Li L, Wang Y, Ma C, Feng J, Deng Z, Xu P: Cometabolic degradation of dibenzofuran and dibenzothiophene by a newly isolated carbazole-degrading Sphingomonas sp. Strain Appl Environ Microbiol 2007, 73(9):2832-2838

24. Li W, Zhang Y, Wang MD, Shi Y: Biodesulfurization of dibenzothiophene and other organic sulfur compounds by a newly isolated Microbacterium strain ZD-M2. FEMS Microbiol Lett 2005, 247(1):45-50.

25. Davoodi-Dehaghani F, Vosoughi M, Ziaee AA: Biodesulfurization of dibenzothiophene by a newly isolated Rhodococcus erythropolis strain. Rev Bior Technol 2010, 101:1102-1105.

26. Ansari F, Prayuenyong P, Tothill IE: Biodesulfurization of dibenzothiophene by Shewanella putrefaciens NCIMB 8768. J Biol Phys Chem 2007, 7:75-77.

27. Baldi F, Pepi M, Fava F: Growth of Rhodosporidium toruloides strain DBVPG6662 on dibenzothiophene crystals and orimulsion. Appl Environ Microbiol 2003, 69:4689-4696.

28. Seo J-S, Keum YS, Cho LLK, Li QX: Degradation of dibenzothiophene and carbazole by Arthrobacter sp. p 1-1. Int Biodeter Biodegr 2006, 58:36-43.

29. Li Y, Li J, Wang C, Wang P: Growth kinetics and phenol biodegradation of psychrotrophic Pseudomonas putida LY1. Bioresour Technol 2010, 17:6740-6744.

30. Carnes EC, Lopez DM, Donegan NP, Cheung A, Gresham H, Timmins GS, Brinker CJ: Confinement-induced quorum sensing of individual Staphylococcus aureus bacteria. Nat Chem Biol 2010, 6:41-45.
31. Siehnel R, Traxler B, An DD, Parsek MR, Schaefer AL, Singh PK: A unique regulator controls the activation threshold of quorum-regulated genes in Pseudomonas aeruginosa. Proc Natl Acad Sci U S A 2010, 107:7916-7921.

32. Crawford DL, GUPTA RK: Oxidation of dibenzothiophene by Cunninghamella elegans. Cur Microbiol 1990, 21:229-231.

33. Bahuguna A, Lily MK, Munjal A, Singh RN, Dangwal K: Desulfurization of dibenzothiophene (DBT) by a novel strain Lysinibacillus sphaericus DMT-7 isolated from diesel contaminated soil. J Environ Scienc 2011, 23(6):975-982.

34. Caro A, Boltes K, Letón P, García-Calvo E: Dibenzothiophene biodesulfurization in resting cell conditions by aerobic bacteria. J Biochem Eng 2007, 35:191-197.

35. Doyle JJ, Doyle JL: Isolation of plant DNA from fresh tissue. Focus 1991 12:13-15.

36. Weisburg WG, Barns SM, Pelletier DA, Lane DJ: 16S ribosomal DNA amplification for phylogenetic study. J Bacteriol 1991, 173(2):697-703.

37. Erwing B, Green P: Base-calling of automated sequencer traces using phred. II, Error probabilities. Genome Res 1998, 8:186-194.

38. Altschul SF, Gish W, Miller W, Myers EW, Lipman DJ: Basic local alignment search tool. J Mol Biol 1990, 215(3):403-410.

39. Tamura K, Peterson D, Peterson N, Stecher G, Nei M, Kumar S: MEGA5: molecular evolutionary genetics analysis using maximum likelihood, evolutionary distance, and maximum parsimony methods. Mol Biol EV 2011, 28(10):2731-2739.

40. Shavandi M, Sadeghizadeh M, Khajeh K, Mohebali G, Zomorodipour A: Genomic structure and promoter analysis of the Dsz operon for dibenzothiophene biodesulfurization from Gordonia alkanivorans RIPI90A. App/ Gen Mol Biotechnol 2010, 87:1455-1461.

41. Loguercio LL, Barreto ML, Rocha TL, Santos CG, Teixeira FF, Paiva E: Combined analysis of supernatant-based feeding bioassays and PCR as a first-tier screening strategy for Vip-derived activities in Bacillus thuringiensis strains effective against tropical fall armyworm. J Appl Microbiol 2002, 93:269-277.

doi:10.1186/s12866-014-0257-8

Cite this article as: Buzanello et al:: A novel Bacillus pumilus-related strain from tropical landfarm soil is capable of rapid dibenzothiophene degradation and biodesulfurization. BMC Microbiology 2014 14:257.

\section{Submit your next manuscript to BioMed Central and take full advantage of:}

- Convenient online submission

- Thorough peer review

- No space constraints or color figure charges

- Immediate publication on acceptance

- Inclusion in PubMed, CAS, Scopus and Google Scholar

- Research which is freely available for redistribution 